\title{
Group Work: Facilitating the Learning of International and Domestic Undergraduate Nursing Students
}

\author{
Julie Shaw ${ }^{1}$, Creina Mitchell' ${ }^{1}$ Letitia Del Fabbro ${ }^{1}$ \\ 'Lecturer, School of Nursing and Midwifery, Menzies Health Institute Queensland, Griffith Health, Griffith University, OLD 4222, Australia
}

\begin{abstract}
Background: Devising innovative strategies to address internationalization is a contemporary challenge for universities. A Participatory Action Research (PAR) project was undertaken to identify issues for international nursing students and their teachers. The findings identified group work as a teaching strategy potentially useful to facilitate international student learning. Methods: The educational intervention of structured group work was planned and implemented in one subject of a Nursing degree. Groups of four to five students were formed with one or two international students per group. Structural support was provided by the teacher until the student was learning independently, the traditional view of scaffolding. The group work also encouraged students to learn from one another, a contemporary understanding of scaffolding. Evaluation of the group work teaching strategy occurred via anonymous, self-completed student surveys. The student experience data were analysed using descriptive statistical techniques, and free text comments were analysed using content analysis. Results: Over $85 \%$ of respondents positively rated the group work experience. Overwhelmingly, students reported that class discussions and sharing nursing experiences positively influenced their learning and facilitated exchange of knowledge about nursing issues from an international perspective. Discussion: This evaluation of a structured group work process supports the use of group work in engaging students in learning, adding to our understanding of purposeful scaffolding as a pathway to enhance learning for both international and domestic students. By explicitly using group work within the curriculum, educators can promote student learning, a scholarly approach to teaching and internationalization of the curriculum.
\end{abstract}

Keywords: Group work, international students, internationalization, learning and teaching, scaffolding, student diversity, student experience

\section{Background}

In recent years, the number of international students studying in Australia has increased. ${ }^{[1]}$ This increase adds layers of diversity to student cohorts and adds to the complexity of teaching environments. ${ }^{[2]}$ The student experience in Australia remains a challenge for international students given the complex interplay between their transition to the Australian study environment, quality of learning, learning outcomes

\begin{tabular}{|l|l|}
\hline \multicolumn{2}{|c|}{ Access this article online } \\
\hline Quick Response Code: & Website: \\
\hline & www.educationforhealth.net \\
\cline { 2 - 2 } & \\
\hline
\end{tabular}

and satisfaction. ${ }^{[3]}$ For domestic students, the increasing number of international students also adds complexity to their interpersonal interactions as well as presenting them with opportunities to garner valuable international insights. The term 'international student' refers to students that are studying outside their country of citizenship, and 'domestic student' refers to students that are citizens of the country in which they are studying. ${ }^{[4]}$ The premise of this paper is that a specific teaching strategy, namely structured and scaffolded group work, is a beneficial teaching strategy that can be used to improve student experiences for international and domestic students as well as foster internationalization.

Higher numbers of international students and the increasing general awareness of global issues have underpinned internationalization in the higher education sector. Internationalization includes “... students acquiring global

Address for correspondence:

Ms. Julie Shaw, Lecturer, School of Nursing and Midwifery - Gold Coast, Gold Coast Campus, Griffith University, OLD 4222, Australia. E-mail: j.shaw@griffith.edu.au 
perspectives, an appreciation of the social and cultural construction of knowledge and being prepared to perform in international and multicultural contexts". ${ }^{[5]}$ Australian universities have committed to strategies including internationalization of the curriculum ${ }^{[6]}$ and enhancing academic literacy, to improve the international student experience. 'Student experience' refers to all facets of student life including social and welfare with the focus being the academic experience. ${ }^{[7]}$ Student experience has become an accepted term in higher education inferring that ".... good student experience is one that combines good quality with value for money". ${ }^{[8]}$ The International Student Barometer (ISB) survey ${ }^{[0]}$ draws together student expectations and satisfaction data at an international level, and in Australia, universities administer anonymous surveys at the local level to benchmark the student experience nationally. In Australia, as elsewhere, attention has been drawn to the experience and satisfaction of international students studying in Australia. ${ }^{[3]}$ International student satisfaction with the quality of education is reportedly lower than domestic student satisfaction. ${ }^{[10]}$

The international diversity of the student body presents challenges and opportunities for students; this diversity also influences the experience of academic staff. International students have a wide variety of previous learning experiences including learning styles, preparation and academic literacy experience. ${ }^{[1]]}$ For the education of health profession students, including nursing, clinical practice norms and the extent of past clinical placement experience is also varied. ${ }^{[12]}$ Academic staff require a toolkit of teaching strategies to accommodate this diversity.

The use of group work in higher education is well recognized as an effective educational strategy for active learning ${ }^{[13,14]}$ and student collaboration. ${ }^{[6,15]} \mathrm{A}$ key element of group work is sharing. Sharing can relate to tasks, motivations, experiences or goals that the group aims to meet and is affected by the group dynamic, or the interaction and structure of the group. ${ }^{[16]}$ Importantly, this means that group members need to be able to communicate effectively within the group to attain group goals. Structure refers to the group members and the power relationships between members and individual responsibilities of members in working towards meeting the group goal. Further, group work is more than just adding to curriculum content; it is a strategy that enables all students, domestic and international, to discuss issues, learn and deepen student understanding of a content area. ${ }^{[6]}$

Students also need to be supported in group work with activities scaffolded to facilitate group cohesion and learning. Scaffolding is a term that has been loosely used in education. In the traditional form, scaffolding refers to temporary structural support provided by the teacher until the student is independently learning. ${ }^{[17,18]} \mathrm{A}$ more recent perspective of scaffolding refers to individual learning from "bi-directional interaction" within a group with students learning from one another. $^{[19]}$

Further work is needed to extend our understanding of group work for engaging students in internationalization. ${ }^{[20]}$ Relevant studies of the use of group work have included the investigation of interaction and influence in culturally mixed groups, ${ }^{[21]}$ student perceived challenges in multicultural group work, ${ }^{[20]}$ domestic student experiences and outcomes of group work, ${ }^{[22]}$ the effects of group work on English language competence of international students ${ }^{[23]}$ and the impact of interpersonal trust relationships on student willingness to share in group work. ${ }^{[24]}$

\section{Setting}

Academic staff in the School of Nursing and Midwifery at one Australian University initiated a Participatory Action Research (PAR) project to investigate and improve the experience of both international students and their teachers simultaneously, taking into account local and contextual issues. ${ }^{[25]}$ Action research is an effective way to improve teaching and learning. ${ }^{[25,26]}$ The steps in the cyclical process of this PAR included planning, acting, observing and evaluating. ${ }^{[27]}$ The project aimed to identify key learning and teaching issues, plan strategies to address these, and implement and evaluate the strategies. ${ }^{[28]}$

The initial planning phase of the PAR process included interviews with academic teaching staff $(n=14)$ and international student $(n=12)$ volunteers. These interviews were analysed and coded. ${ }^{[29]} \mathrm{A}$ key issue identified by both students and staff in this planning phase was the need to improve group work processes. In addition to group work being identified as a key action area for learning enhancement, academic teaching staff worked together to plan teaching and learning strategies for enhanced group work. Subsequently learning strategies to promote interaction between international and domestic students were planned for one subject of the Bachelor of Nursing degree with the aim of providing more opportunities for group members to learn from one another and foster teamwork.

\section{Methods}

\section{Educational intervention}

The subject selected for the implementation of the group work strategy was a final year compulsory subject in the Bachelor of Nursing degree entitled Contemporary Nursing. The aim of the Contemporary Nursing subject was to expose nursing students to current issues in the health sector taking into consideration the nursing profession, health and health services, economics, society and politics. Assessment in this 
subject already included a group PowerPoint presentation where students were required to work together in small teams across the semester to research, develop and present their findings on a current nursing issue such as workforce, bullying or primary health.

The subject involved five weeks of face-to-face teaching made up of weekly seminars of three hours duration. During the seminars, a one hour lecture was provided; students then moved to their small groups to collaborate on learning activities. These activities addressed subject content areas and aimed at exploring knowledge on the weekly topic and developing group cohesion in a safe learning space with the support of the teacher. In the last hour, students remained in their groups to work on their group assessment task with the teacher present to provide support in regard to subject content, assessment and group functioning.

\section{Teaching strategies}

The key strategies involved in this intervention included:

1. Modifying the structure and function of the student groups (limiting size and composition);

2. Engaging students in defined small group activities to promote teamwork;

3. Student negotiation of a small group contract or agreement to guide role definition and development in the group work process throughout the semester; and

4. An emphasis on sharing experiences (e.g., international experiences).

Groups were limited by the teacher to four to five students to allow students to develop working relationships with all members and ensure all students would have responsibilities in the assessment task. Each group was required to have at least one international student member to ensure that all students had international exposure and that international students had contact with more than one domestic student. Student groups were self-selected. Those groups, which had difficulty meeting the one international student group requirement, were allocated an international student who was willing to move from a group that had more than one international student member. In the same way, international students beginning the subject late in the semester were allocated to groups willing to have an extra international student member. Groups were limited to two international students per group as in previous cohorts those groups made up of newly arrived international students only had achieved lower grades in these assessments. The 152 individual students made up 32 groups.

Group work was scaffolded across the five weeks of teaching. Scaffolding was used in this project in its traditional form by providing a framework for students to begin interacting in groups. In week one, students were asked to form their groups and undertake activities to create the basis for working relationships. For example, simple 'getting to know you' activities ending with each group presenting their group to the class, identifying group members and what each member brought to the group. By the end of week one, students were expected to have completed the 'getting to know you activities' and to have signed the group contract. The group contract included agreement on group member responsibilities, confirmation of future meeting dates and times, and the exchange of contact details. The contract was a strategy used to promote group work when face-to-face classes were completed and third-year students were on clinical placement. The contract was also seen as a tool for students to revisit and use to resolve issues when groups were not functioning effectively.

In the following weeks, group activities were built around weekly topics with team building developing as students worked on new topics. In these weeks, scaffolding reflected both the traditional as well as the more recent perspective. Students learned more about one another and nursing when they shared their experiences and discussed topics such as: Nurse education, both Australian and international; nursing workforce issues including the 'brain drain' from developing countries; and immunization programs, both Australian and international. Each week, the group activities that focused on the weekly topic were followed by group work on the group assessment task. In this way, students were able to use the teacher as a resource on the topic and as a support for group malfunction.

\section{Data collection and analysis}

At the end of semester, students were asked to volunteer to evaluate the strategy. Student volunteers were asked to self-complete a short evaluative survey comprised of six 4-point Likert scale questions with answers ranging from 1: 'Not at all helpful' to 4: 'Very helpful'. The survey tool also included open-ended questions and the option to make additional free comments. Data were de-identified prior to analysis to maintain confidentiality.

Ethics approval for the project was granted by the University Human Research and Ethics Committee prior to the commencement of the project.

\section{Results}

The student group of 152 students was made up of both second $(n=32)$ and third year $(n=120)$ nursing students, some of whom were in their first semester at university $(n=21)$ and in the first six months of living in a foreign country. The student cohort was diverse with international students from the Middle East, South East Asia, Europe, Canada, North and South America and New Zealand. Apart from differences in 
higher education experience and expectations, there were also differences in gender, age, religion, life experience, country of origin, residential status, English language proficiency and culture. The diversity of the student group, while at times challenging for the teacher and students alike, also created opportunities for learning, in particular in regard to international practices in nursing. ${ }^{[16]}$

Of the 152 students enrolled, 108 (71\%) fully or partially completed the evaluation. Of these, 77 (71\%) were domestic students and 31 (29\%) international students. Over $85 \%$ of respondents positively rated working in small groups (mean 3.42; standard deviation 0.92), sharing nursing experiences $(3.59 ; 0.60)$, and class discussions $(3.57 ; 0.55)$. Overwhelmingly, students viewed their experience of class discussions and sharing nursing experiences as positively influencing their learning. There were no notable differences between the responses of international and domestic students [Table 1].

Student respondents to the short evaluation survey identified the benefits of group work including, sharing personal nursing experiences and discussing current issues highlighting how the subject content provided a rich internationalization experience:

“... including international students in group was a great learning experience due to the exposure of different perspectives".

"Discussion about current issues related to nursing and health areas, and involvement of domestic and international students together for the presentation, which helps to get information from different countries about health and nursing issues".

Similarly, international students commented on the benefits of group work in getting to know domestic students more closely including the processes of sharing experiences and the need to converse in English with native speakers.

"We came to know more closely their lifestyle".

"Working in small group was very interesting; due to this we were able to share our nursing experiences with own group members".

The evaluation highlighted the helpfulness of the group work teaching and learning strategies; however, of the 108 survey respondents, there were 3 students who did not support the strategies. Their comments included:

"The requirements to include an international student... increased the other group members' workloads".

"International students ... were singled out and made to feel different".

In addition to the short evaluation survey, the research team reviewed other data sources to add to the evaluation of this intervention. The short evaluation survey responses were triangulated with the university-wide anonymous student evaluation feedback and the assessment results for the course. The university-wide student evaluation of the subject supported the effectiveness of the group work strategies. The results of the student group assessments provided evidence to support successful learning. Following this intervention, the overall standard of student results improved. Specifically, international students were successful in the group assessment whereas, in previous years, it was common to have groups composed of international students only and these groups fared poorly in the group presentation assessment item (the standard data collected in past years for this course does not contain international student identifiers and therefore precludes direct comparison with current data).

\section{Discussion}

Moving to a foreign country is difficult, and studying in a different education system compounds that difficulty. Scaffolded group work activity provides a pathway for international students to mix with domestic students, practice their English language skills with fast-talking native speakers and learn about the contemporary issues across Australian and international health systems. Likewise, working in groups that included international students broadened the exposure of domestic students to a variety of nursing views and experiences not encountered when working with domestic students alone.

In this study, a structured group work process was implemented as a fundamental building block to learning in a subject within a Bachelor of Nursing degree. From the outset of teaching in the subject, all students were made aware of the cogent place of group work in the subjects' learning and assessment process. The structured group work process mandated the inclusion and

Table 1: Evaluation of teaching strategies by domestic and international students

\begin{tabular}{|c|c|c|c|c|c|c|}
\hline \multirow[t]{2}{*}{ Strategy evaluated } & \multicolumn{2}{|c|}{ Domestic students $n(\%)$} & \multicolumn{2}{|c|}{ International students $n(\%)$} & \multicolumn{2}{|c|}{ All students $n(\%)$} \\
\hline & Helpful & Not helpful & Helpful & Not helpful & Helpful & Not helpful \\
\hline Sharing experiences & $66(91.7)$ & $6(8.3)$ & $30(100.0)$ & $0(0.0)$ & $96(94.1)$ & $6(5.9)$ \\
\hline Class discussion & $64(88.9)$ & $8(11.1)$ & 28 (93.3) & $2(6.7)$ & $92(90.2)$ & $10(9.8)$ \\
\hline Work in small groups & $62(87.3)$ & $9(12.7)$ & $28(93.3)$ & $2(6.7)$ & $90(89.1)$ & $11(10.9)$ \\
\hline
\end{tabular}


integration of an international student when each group was formed, and students entered into an agreement or contract to work within the groups for the duration of the study period.

While this study was conducted at a single site in a School of Nursing and Midwifery at an Australian University, the group work strategies are relevant to other study contexts and student cohorts, especially given the international diversity of student groups in most university environments. Group work is not always welcomed by students due to claims of unfair distribution of work, non-engaged group members and poor communication ${ }^{[30]}$ that can result in conflict and lead to the breakdown of groups. The literature suggests that adding international students to a group increases the complexity of group work with a common perception that international students demand more of group members. ${ }^{[31]}$

Additionally, the literature reminds us that different students have different educational expectations. ${ }^{[31]}$ For example, international students expect to learn about and integrate into a new culture, while domestic students may not have this expectation of their studies and feel that group work with international students is detrimental to academic performance. ${ }^{[32]}$ A lack of understanding of culture can accentuate the student perceived difficulties of group work, especially when accepted norms of communication and decision-making are not universally understood. ${ }^{[5,20]}$

In this study, the group work intervention strategies were implemented using a scaffolded process of defining group structure and function, engaging students in defined activities, the negotiation of group work agreements and an emphasis on sharing experiences. This process and these elements were essential to the success of the intervention and laid the foundation for the in-depth exchange of knowledge and understandings between the students. The majority of students appreciated and welcomed the strategies to enhance group work processes. Through the provision of a framework for group interaction and the engagement of students in group work class activities, the teacher strategically facilitated and promoted teamwork between domestic and international students, fostering information sharing and group discussion, resulting in student-to-student learning.

Group work, which includes at least one international student in each group as part of a structured group work process, is an effective strategy to enhance learning for both domestic and international students and promotes internationalization of the curriculum. The structured organization of groups resulted in an increased depth of engagement with the course content within these groups.

This study provides a scholarly approach to learning, and the strategies can be used by educators to promote student engagement in group work and internationalization. The group work processes may add depth to a teachers' toolkit of teaching strategies, building on a long tradition of small group work and facilitation. ${ }^{[33]}$ These strategies enhanced group cohesion and did not impact significantly on teaching workload or time. That this intervention took place within a broader PAR project was an advantage as a readiness for change and improvement was apparent in the workplace culture. In the future, it would be very interesting to implement similar teaching improvement interventions across several subjects within a degree program and to continually evaluate their influence over time.

\section{Acknowledgments}

Thanks to staff and student participants. The Participatory Action Research project was supported by a Griffith University Learning and Teaching grant.

\section{References}

1. Australian Bureau of Statistics. Overseas Students in Perspectives on Migrants 2007. [serial online]. Canberra: ABS Publication 3416.0, Austats; 2009.

2. Barker M, Troth A, Back A. Dealing with International University Students: Attitudes and Issues for Teaching and Support Staff. Proceedings of the $10^{\text {th }}$ Annual International Conference on Post-compulsory Education and Training. December 3-5, Gold Coast, Australia; 2002.

3. Department of Education, Employment and Workplace Relations. Australian Higher Education: Final Report. Canberra: Australian Government Publishing Services; 2008.

4. Guthrie JW, editor. Encyclopedia of Education. $2^{\text {nd }}$ ed., Vol. 4. New York: Macmillian, Gale, Cengage Learning, U.S. Colleges and Universities; 2006. p. 1310-8.

5. Burdett J, Crossman J. Engaging international students: An analysis of the Australian Universities Quality Agency (AUQA) reports. Qual Assur Educ 2012;20:207-22.

6. Carroll J, Ryan J, editors. Teaching International Students: Improving Learning for All. New York: Routledge; 2005.

7. Morgan M, editor. Improving the Student Experience: A Practical Guide for Universities and Colleges. UK: Routledge; 2011.

8. Staddon E, Standish P. Improving the student experience. J Philos Educ 2012;46:631-48.

9. Australian Education International. Internationals Student Survey 2012: Overview Report. Canberra: Australian Government Printers; 2013.

10. Australian Education International. 2007 Follow-up International Student Survey: Higher Education. Canberra: Australian Government; 2008.

11. Shaw J, Moore P, Gandhidasan S. Educational acculturation and academic integrity; outcomes of an intervention subject for international postgraduate public health students. J Acad Lang Learn 2007;1:A55-66.

12. Deluca EK. Crossing cultures: The lived experience of Jordanian graduate students in nursing: A qualitative study. Int J Nurs Stud 2005;42:657-63.

13. Meyers C, Jones TB. Promoting Active Learning. Strategies for the College Classroom. California: Jossey Bass; 1993. 
14. Arkoudis S. Teaching International Students: Strategies to Enhance Learning. Melbourne: Centre for the Study of Higher Education; 2007.

15. Singaram VS, Dolmans DH, Lachman N, van der Vleuten CP. Perceptions of problem-based learning (PBL) group effectiveness in a socially-culturally diverse medical student population. Educ Health (Abingdon) 2008;21:116.

16. Fisher BA, Ellis DG. Small Group Decision Making. $3^{\text {rd }}$ ed. New York: McGraw Hill; 1990.

17. Benson BK. Scaffolding. Engl J 1997;86:126-7.

18. Lajoie SP. Extending the scaffolding metaphor. Instrum Sci 2005;33:541-57.

19. Panselinas G, Komis V. Scaffolding through talk in group learning. Think Skills Creat 2009;4:86-103.

20. Popov V, Brinkman D, Biemans HJ, Mulder M, Utznetsov A, Noroozi O. Multicultural student group work in higher education: An explorative case study on challenges as perceived by students. Int J Intercult Relat 2012;32:302-7.

21. Cotton DR, George R, Joyner M. Interaction and influence in culturally mixed groups. Innov Educ Teach Int 2013;5:272-83.

22. Rafferty PD. Group work experiences: Domestic MBA student experience and outcomes when working with international students. J Further High Educ 2011;37:737-49.

23. Xue M. Effects of group work on English communication competence of Chinese international graduates in United States institutions of higher education. Qual Rep 2013;18:1-19.

24. Analoui BJ, Sambrook S, Doloriert CH. Engaging students in group work to maximise knowledge sharing and use. Int J Manage Educ 2014; $12: 35-43$
25. Kember D, Jones A. Reflective Teaching and Learning in the Health Professions: Action Research in Professional Education. Oxford: Blackwell Science; 2001.

26. Yasmeen G. Action research: An approach for teachers in higher education. The Turk Online J Educ Technol 2008;7:46-53.

27. McTaggart R. Principles for participatory action research. Adult Educ Q 1991;4:168-87.

28. Del Fabbro L, Mitchell C, Shaw J. Learning among nursing faculty: Insights from a participatory action research project about teaching international students. J Nurs Educ 2015;54:153-8.

29. Creswell JW. Qualitative Inquiry and Research Design: Choosing among the Five Approaches. $2^{\text {nd }}$ ed. London: Sage; 2007.

30. Chapman H. Towards effective group-work in nurse education. Nurse Educ 2006;26:298-303.

31. Chiles P, Care L. Exploring student group work needs in the context of internationalisation using a creative visual method. Int J High Educ 2012;1:21-32.

32. Summers M, Volet S. Student's attitudes towards culturally mixed groups on international campuses: Impact of participation in diverse and non-diverse groups. Stud High Educ 2008;33:357-70.

33. Tuckman BW, Jensen MA. Stages of small-group development revisited. Group Organ Stud 1977;2:419-27.

How to cite this article: Shaw J, Mitchell C, Fabbro LD. Group work: Facilitating the learning of international and domestic undergraduate nursing students. Educ Health 2015;28:124-9.

Source of Support: Griffith University Learning and Teaching grant Conflict of Interest: None declared. 